Louisiana State University

LSU Digital Commons

Faculty Publications

Department of Biological Sciences

4-1-2007

\title{
A SINE-based dichotomous key for primate identification
}

\author{
Scott W. Herke \\ Center for BioModular Multi-Scale Systems \\ Jinchuan Xing \\ Center for BioModular Multi-Scale Systems \\ David A. Ray \\ West Virginia University \\ Jacquelyn W. Zimmerman \\ Center for BioModular Multi-Scale Systems \\ Richard Cordaux \\ Center for BioModular Multi-Scale Systems
}

See next page for additional authors

Follow this and additional works at: https://digitalcommons.Isu.edu/biosci_pubs

\section{Recommended Citation}

Herke, S., Xing, J., Ray, D., Zimmerman, J., Cordaux, R., \& Batzer, M. (2007). A SINE-based dichotomous key for primate identification. Gene, 390 (1-2), 39-51. https://doi.org/10.1016/j.gene.2006.08.015

This Article is brought to you for free and open access by the Department of Biological Sciences at LSU Digital Commons. It has been accepted for inclusion in Faculty Publications by an authorized administrator of LSU Digital Commons. For more information, please contact ir@lsu.edu. 
Authors

Scott W. Herke, Jinchuan Xing, David A. Ray, Jacquelyn W. Zimmerman, Richard Cordaux, and Mark A.

Batzer 


\title{
A SINE-based dichotomous key for primate identification
}

\author{
Scott W. Herke ${ }^{a}$, Jinchuan Xing ${ }^{\text {a }}$, David A. Ray ${ }^{\text {b }}$, Jacquelyn W. Zimmerman ${ }^{\text {a }}$, \\ Richard Cordaux ${ }^{\text {a }}$, Mark A. Batzer ${ }^{\mathrm{a}, *}$ \\ a Department of Biological Sciences, Biological Computation and Visualization Center, Center for Bio-Modular Microsystems, \\ Louisiana State University, 202 Life Sciences Building, Baton Rouge, LA 70803, United States \\ ${ }^{\mathrm{b}}$ Department of Biology, 53 Campus Drive, West Virginia University, Morgantown, WV 26506, USA
}

Received 28 June 2006; received in revised form 1 August 2006; accepted 2 August 2006

Available online 30 August 2006

\begin{abstract}
For DNA samples or 'divorced' tissues, identifying the organism from which they were taken generally requires some type of analytical method. The ideal approach would be robust even in the hands of a novice, requiring minimal equipment, time, and effort. Genotyping SINEs (Short INterspersed Elements) is such an approach as it requires only PCR-related equipment, and the analysis consists solely of interpreting fragment sizes in agarose gels. Modern primate genomes are known to contain lineage-specific insertions of Alu elements (a primate-specific SINE); thus, to demonstrate the utility of this approach, we used members of the Alu family to identify DNA samples from evolutionarily divergent primate species. For each node of a combined phylogenetic tree (56 species; $n=8$ [Hominids]; 11 [New World monkeys]; 21 [Old World monkeys]; 2 [Tarsiformes]; and, 14 [Strepsirrhines]), we tested loci ( $>400$ in total) from prior phylogenetic studies as well as newly identified elements for their ability to amplify in all 56 species. Ultimately, 195 loci were selected for inclusion in this Alu-based key for primate identification. This dichotomous SINE-based key is best used through hierarchical amplification, with the starting point determined by the level of initial uncertainty regarding sample origin. With newly emerging genome databases, finding informative retrotransposon insertions is becoming much more rapid; thus, the general principle of using SINEs to identify organisms is broadly applicable.
\end{abstract}

(C) 2006 Elsevier B.V. All rights reserved.

Keywords: Alu; Mobile elements; Retrotransposons

\section{Introduction}

Unless definitive proof already exists, identifying the organism from which DNA samples, and often even tissues, were taken is a crucial step during biological and medical studies. For instance, researchers may receive DNA from sources that lack proof of its origin or samples taken in the field from 'divorced' tissues such as hair or feces (Kohn et al., 1995;

Abbreviations: numtDNA, nuclear pseudogene of mitochondrial origin; PCR, polymerase chain reaction; SINE, Short INterspersed Element; TE, trisEDTA; H, Hominid; OWM, Old World monkey; NWM, New World monkey; IPBIR, Integrated Primate Biomaterials and Information Resource; IUPAC, International Union of Pure and Applied Chemistry; NISC, NIH Intramural Sequencing Center.

* Corresponding author. Tel.: +1 225578 7102; fax: +1 2255787113 .

E-mail address: mbatzer@1su.edu (M.A. Batzer).
Taberlet et al., 1997; Lathuilliere et al., 2001; Matsubara et al., 2005). Further, cross-contamination can occur within cell cultures grown in the presence of lines from multiple species and within concurrent large-scale DNA extractions from multiple species. Even previously documented samples may lose their labels or be cross-contaminated. In addition, investigations of the illegal wildlife trade require methods for documenting the identity of seized products (Hsieh et al., 2003; Malisa et al., 2005; Yan et al., 2005; Domingo-Roura et al., 2006). Unless the identities of the sample organisms are properly established and cross-contamination issues are detected, future analyses based on these types of samples can be seriously compromised.

In many cases, molecular techniques are required for a positive identification of undocumented samples. The ideal approach would require minimal equipment, time, and effort; further, it would be robust even in the hands of a novice. Genotyping mitochondrial DNA (mtDNA) is one of the 
commonly used procedures (Kohn et al., 1995; Palumbi and Cipriano, 1998; Malisa et al., 2005), and DNA barcoding based on mtDNA sequences has been advocated for the identification of species (Hebert et al., 2004). Even the Integrated Primate Biomaterials and Information Resource (www.IPBIR.org) uses mtDNA (mitochondrial cytochrome $c$ oxidase subunit I) to verify the identity of samples and is generating a database of 'DNA barcodes' for primates (Lorenz et al., 2005). However, the use of mtDNA is complicated by taxon-specific patterns of 'universal primer' failure, as well as by the amplification or coamplification of nuclear pseudogenes (numtDNA) of mitochondrial origins (Moritz and Cicero, 2004; Lorenz et al., 2005).

Recently, retrotransposons were used to develop characteristic 'fingerprints' for 10 individual human cell lines to ensure that each line used in an experiment was the expected cell line (Ustyugova et al., 2005). Thus, genotyping retrotransposons (i.e., mobile elements) offers another approach for ensuring accurate identification of DNA and tissue samples with respect to their organismal origins. SINEs (Short INterspersed Elements) are a class of non-autonomous mobile elements that are $<500 \mathrm{bp}$ in length and have no open reading frames. Given that they are ubiquitous in mammalian genomes as well as in many non-mammalian genomes (Deininger and Batzer, 2002; Okada et al., 2004; Ray et al., in press), SINEs are well known as powerful tools for systematic biologists (Hamdi et al., 1999; Hillis, 1999; Shedlock and Okada, 2000; Walker et al., 2004a) and forensic scientists (Walker et al., 2003a,b; Walker et al., 2004b; Ray et al., 2005a; Walker et al., 2005). For example, Waddell et al. (2001) stated that, while DNA sequence analysis can help set up hypothesized clades of placental genomes, SINEs are essential to testing them. In that context, the close relationship of cetaceans (whales, dolphins, and porpoises) to Hippopotamidae was established through an analysis of SINE data (Nikaido et al., 1999). In a different vein, Walker et al. (2003a) demonstrated that SINEs could be used to distinguish bovine, porcine, chicken and ruminant species from as little as $0.1 \mathrm{pg}$ of starting DNA, offering a more sensitive method for detecting products relevant to bovine spongiform encephalopathy. Finally, SINEs have been used for several phylogenetic studies of Mammals, including the Primate order (Schmitz et al., 2001; Salem et al., 2003b; Roos et al., 2004; Ray et al., 2005b; Schmitz et al., 2005; Xing et al., 2005; Kriegs et al., 2006; Nikaido et al., 2006).

Alu elements are primate-specific SINEs, with a full length of $\sim 300 \mathrm{bp}$. As the most successful SINEs in primate genomes, these mobile elements have proliferated during the primate radiation to more than one million copies ( $\sim 10 \%$ by mass $)$ in the human genome (Lander et al., 2001; Batzer and Deininger, 2002). The study of Alu elements has produced definitive pictures regarding the phylogenies of hominids (Salem et al., 2003b), Old World monkeys (Xing et al., 2005), and New World monkeys (Ray et al., 2005b). Even the hypothesized close relationship between tarsiers and anthropoids received support from Alu elements (Schmitz et al., 2001; Roos et al., 2004). Thus, to demonstrate the utility of a dichotomous SINEbased key, we have focused on the use of Alu elements for the identification of primate DNA samples.
The diverse order of primates is currently divided into two major groups, Strepsirrhini and Haplorhini (see phylogenetic review by Disotell, 2003). The Strepsirrhini include the Lorisiformes ( $\sim 8$ genera) and the Lemuriformes ( $\sim 14$ genera). The Haplorhini include the Tarsiformes (1 genus) and the Anthropoidea, which is further subdivided into the Platyrrhini (New World monkeys [NWM], $\sim 16$ genera) and the Catarrhini. Cercopithecidae (Old World monkeys [OWM], $\sim 21$ genera) and Hominoidea (Hominids $[\mathrm{H}], \sim 5$ genera) comprise the Catarrhini. For a combined phylogenetic tree (56 species; $n=8$ $[\mathrm{H}] ; 11$ [NWM]; 21 [OWM]; 2 [Tarsiformes]; and, 14 [Strepsirrhines]), we tested 443 loci for amplification in all five currently existing primate groups: (A) 362 anthropoid loci which came from four previous phylogenetic studies (Salem et al., 2003b; Han et al., 2005; Ray et al., 2005b; Xing et al., 2005), including 25 existing OWM loci for which we redesigned primers to improve amplification efficiency; and, (B) 81 new loci that we characterized to provide resolution at the deepest nodes in the combined phylogenetic tree (24 loci), to identify members of Strepsirrhines (31 loci), or to define several terminal branches in the tree (26 loci).

The benefits of a SINE-based dichotomous key are amply demonstrated by this work, which is based exclusively on Alu elements. For instance, the 195 loci contained in this dataset can be used to specifically identify 28 terminal branches of our combined primate phylogenetic tree; further, samples derived from the remaining 28 species (and even species not included in the analysis) can at least be partially identified by the internal node loci. As such, the key is a valuable tool for clarifying the identity of primate samples which lack documented provenance, to check for cross-contamination of primate DNA samples, and to identify primate products seized from the illegal wildlife trade.

\section{Materials and methods}

\subsection{DNA samples}

Sufficient amounts of genomic DNA were available for only nine species; very limited amounts of genomic DNA were available for the other 47 species (Appendix A). Thus, those samples of limited quantity were first subjected to whole genome pre-amplification using the Genomiphi genome amplification kit (Amersham, Sunnyvale, CA) following the manufacturer's instructions. The genome-amplified DNA was ethanol precipitated, dried, and resuspended in 1× TE. Based on $\mathrm{A}_{260}$ readings, all samples were diluted in $1 \times \mathrm{TE}$ to $\sim 20 \mathrm{ng} / \mu \mathrm{l}$, and then used as templates for PCR assays.

\subsection{Primer design}

The vast majority of the primers tested here were designed previously (Salem et al., 2003b; Han et al., 2005; Ray et al., 2005b; Xing et al., 2005). However, additional primers were designed for: (1) new loci in Hylobates, Pongo, Gorilla, and Pan; (2) some existing OWM loci; and, (3) new loci that would group various combinations of anthropoid primates or members of Strepsirrhini. Loci specific for Hylobates and 
Pongo were characterized as previously described (Xing et al., 2005), and flanking oligonucleotide primers for PCR amplification of each Alu element were designed in Primer3 (Rozen and Skaletsky, 2000). From the phylogenetic studies, unless a locus had been amplified from more than $\sim 75 \%$ of the species in the original analyses, we did not include it in the current analysis (except for terminal branch loci). Nevertheless, PCR amplifications frequently failed when $\mathrm{H}$ and OWM primers were used on species not included in the original analyses; thus, we redesigned primers whenever possible based on multiple species sequence alignments. To this end, we first linked (by 20 N's) each pair of forward and reverse (reverse-complemented) primers and used them as queries in BLAST (Basic Local Alignment Search Tool, both $\mathrm{nr}$ and htgs databases, available at http://www.ensembl.org/multi/blastview; Altschul et al., 1990). Although only human or chimpanzee sequences were returned for the $\mathrm{H}$ primers, useful data were generated for about 25 OWM loci. For each locus, we generated a consensus sequence in BioEdit (ver 7.0.1; Hall, 1999) from the manually adjusted ClustalW alignment (Thompson et al., 1994) of the returned sequences. In regions deemed potentially suitable for primers, clear zones for primer design were created in each consensus sequence by manually converting IUPAC codes to the most appropriate specific bases. All consensus sequences were then processed in Primer3, which generated potential primers only in relatively conserved regions because the program treats IUPAC codes as excluded zones for primer design.

Additional new primer pairs were designed based on genomic scaffolds for 12 primates: Cercopithecus (Chlorocebus) aethiops (DP000029.1); Macaca mulatta (DP000005.1); Papio anubis (AE017182.1); Callicebus moloch (DP000019.1); Callithrix jacchus (DP000014.1); Eulemur macaco macaco (DP000024.1); Lemur catta (DP000004.1); Microcebus murinus (DP000022.1); Otolemur garnettii (DP000013.1); Gorilla gorilla (DP000025.1); Pan troglodytes (DP000016.1); and, Pongo pygmaeus (DP000026.1). All sequences were generated by the NISC Comparative Sequencing Program, and they are orthologous to an $\sim 1.9-\mathrm{Mb}$ region ('Target 1') on human chromosome $7 \mathrm{q} 31.3$ (http://www.nisc.nih.gov). We used MultiPipMaker (http://bio. cse.psu.edu/pipmaker; Schwartz et al., 2000) to generate several alignments of the complete sequences from all 12 non-human primates and a portion of the human chromosome 7 genomic contig (NT_007933.14|Hs7_8090:40831359-42536062); the reference RepeatMasker (http://repeatmasker.genome.washington.edu/) file in each case was derived from the species of interest in that particular alignment. Parameters were set as 'search one strand' and 'chaining', with default sensitivity and time limit settings. The MultiPipMaker 'Verbose text' alignment files were processed in MEGA3 (Kumar et al., 2004) to generate fasta files, which were imported into BioEdit. We then searched the MultiPipMaker PDF output file for $A l u$ insertions that were specific to the species or group of species of interest. After locating a candidate $A l u$ element, we exported $\sim 1500 \mathrm{bp}$ from each sequence in the BioEdit file (centered on the Alu element), excised all gaps, and checked the sequences with RepeatMasker for repeat elements. Primers for suitable loci were designed as described above.

\subsection{PCR analyses}

Initial tests of the existing primers showed that PCR done with relatively low DNA concentrations (e.g., $25 \mathrm{ng}$ ) and a standard annealing time of $30 \mathrm{~s}$ with 32 cycles often failed to generate either empty or filled site fragments for many species (data not shown). The final parameters chosen as optimal for amplifying products from across all 56 species were: $80 \mathrm{ng}$ DNA $(4 \mu 1$ in $1 \times$ Tris-EDTA) in $25 \mu 1$ reactions with an initial denaturation at $94{ }^{\circ} \mathrm{C}(2 \mathrm{~min}) ; 37$ cycles of denaturation at $94{ }^{\circ} \mathrm{C}$ (30 s), optimal annealing temperature (60 s), and extension at $72{ }^{\circ} \mathrm{C}(60 \mathrm{~s})$; and, a final extension at $72{ }^{\circ} \mathrm{C}(5 \mathrm{~min})$. PCR reagents included $200 \mathrm{nM}$ of each oligonucleotide primer, $200 \mu \mathrm{M}$ each dNTP in $50 \mathrm{mM} \mathrm{KCl}, 1.8 \mathrm{mM} \mathrm{MgCl}_{2}, 10 \mathrm{mM}$ Tris- $\mathrm{HCl}$ (pH 8.4), 2.0 units Taq DNA polymerase, and $10 \%$ RediLoad. Resulting PCR products $(\sim 25 \mu \mathrm{l})$ were separated for $25 \mathrm{~min}(325 \mathrm{~V})$ on $2 \%$ Na-borate agarose gels $(15 \times 25 \mathrm{~cm}$; $300 \mathrm{ml}$ ) containing ethidium bromide for visualization by UV fluorescence (Brody and Kern, 2004a,b). Optimal annealing temperatures were initially derived from temperature gradient tests done with two to four divergent species; any further refinements were based on initial primate panel results. Most of the loci developed from the Target 1 scaffold alignments were tested on all non-anthropoid species because the loci provided resolution at the deepest nodes in the combined phylogenetic tree or identified members of Strepsirrhini. In contrast, all other primers were unlikely to efficiently amplify Strepsirrhini loci (due to their high genetic divergence from anthropoid primates), so we tested them only on L. catta, Nycticebus pygmaeus, Galago senegalensis and Tarsius syrichta.

\subsection{DNA sequencing}

Selected PCR products were purified using the Wizard PCR gel purification kit (Promega, Madison, WI) and directly sequenced using chain termination sequencing (Sanger et al., 1977) on an ABI 3130XL Genetic Analyzer. The majority of the $A l u$ elements had already been verified by sequence analysis in the prior phylogenetic studies and the newly developed loci were designed from genomic scaffold data. Thus, we sequenced only those few loci that demonstrated amplification patterns consistent with the independent insertion of $A l u$ elements (GenBank accession numbers DQ822046-DQ822070 and DQ843660-DQ843663).

\section{Results}

\subsection{Dichotomous key branch loci}

For each branch with informative loci, data on primer sequences, expected fragment sizes, annealing temperatures, and branches with atypical PCR results can be found in Appendix B. An ideal primer pair amplified the locus in most species such that a clean, distinct band of the appropriate size for an 'empty' or a 'filled' site was visible in a $2 \%$ agarose gel. While the use of Naborate for electrophoresis allowed for faster and cleaner resolution of the PCR products, the system is completely compatible with 
TBE (Tris-borate-EDTA, which is more commonly used in most laboratories). With respect to loci from which primers generated substantial amounts of non-specific products, apparent independent insertions, or numerous species dropouts, we generally discarded them if changing the annealing temperature or redesigning the primers did not improve the result. With rare exception, only the primers based on Target 1 scaffold sequences gave reliable results within Tarsiformes and Strepsirrhini.

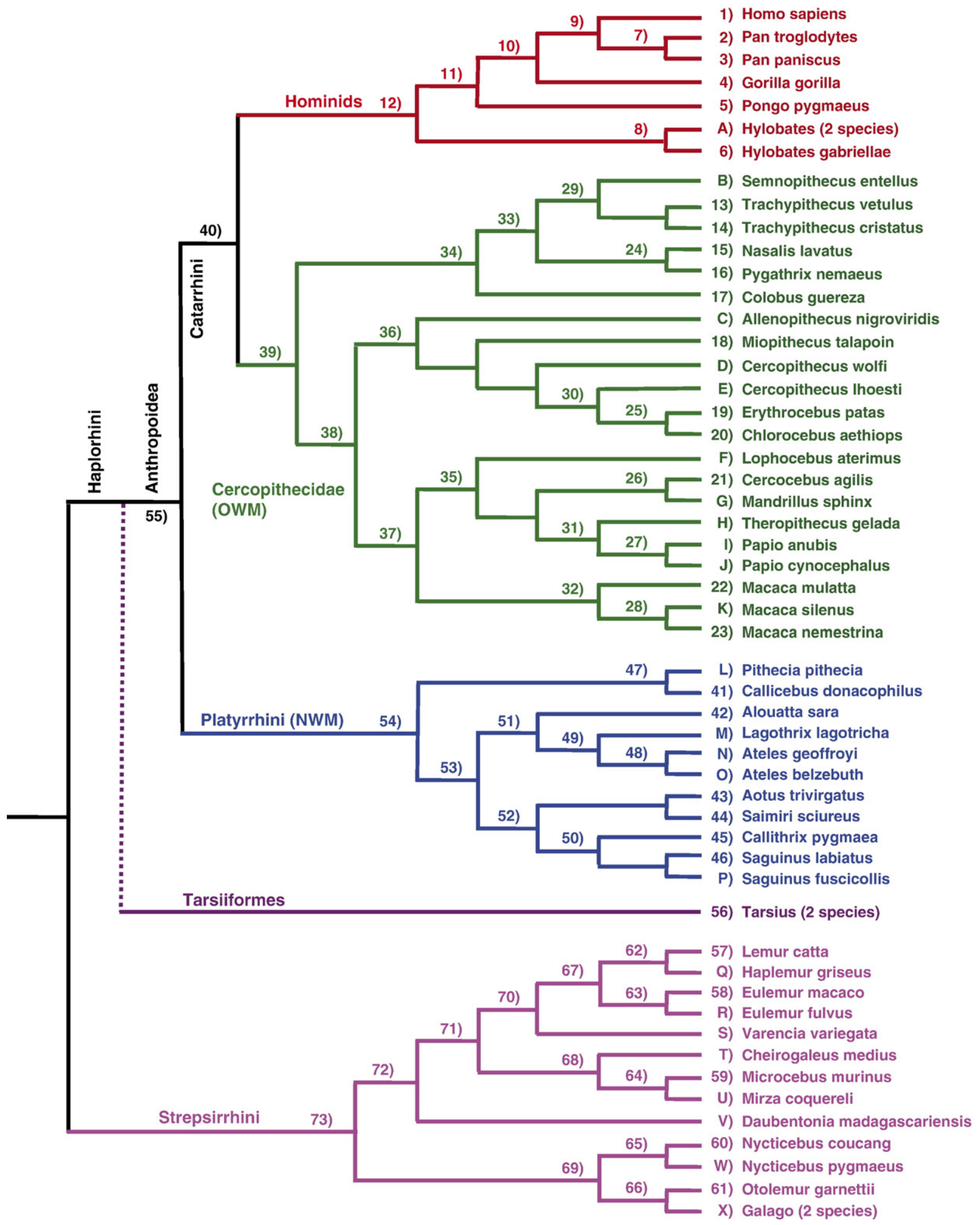

Fig. 1. Combined phylogenetic tree. Numbers indicate branches that are characterized by various $A l u$ insertions; letters are used for terminal branches that are characterized only by internal branch loci. See Appendix B for information on primers that amplify branch-specific loci; typically, at least three loci are listed for each branch. Figs. 2 and 3 depict an example of an identification analysis involving an anthropoid primate DNA sample. 


\subsection{Sequence analysis of problematic loci}

Sequence analysis revealed that the 'filled' site alleles shared by Tarsius and most lemuriformes at locus 'Str-71_C' were independent insertion events (i.e. different $A l u$ elements found within the same small genomic pre-integration site). Further, although the Nycticebus PCR products for locus 'Str-66_A' were initially interpreted as being a small deletion in $N$. pygmaeus and a small insertion in N. coucang (relative to Otolemur and the two Galago spp), neither Nycticebus species actually contained the Alu element ( $\sim 270 \mathrm{bp}$ ) found in our analysis of the Otolemur Target 1 alignment. Instead, there was a truncated independent insertion ( $\sim 50 \mathrm{bp})$ in both $N$. pygmaeus and $N$. coucang and an additional independent insertion ( $270 \mathrm{bp})$ in $N$. coucang. For the 27 Strepsirrhini loci examined, no other cases of independent insertion were detected. For the 11 'anthropoid' loci in which the 'filled' site appeared to be present in species outside the expected clade, sequence analysis showed that those loci were subject to independent insertions or paralogous amplification (two cases).

\subsection{Phylogenetic context}

Phylogenetic results from this analysis (Fig. 1) were entirely consistent with those described previously (Disotell, 2003; Salem et al., 2003b; Ray et al., 2005b; Xing et al., 2005). Given that most of the H, OWM, and NWM loci were already part of those phylogenetic studies, this concurrence was expected. By contrast, the loci designed for distinguishing Strepsirrhini were new and represent additional support for that phylogeny. However, we were unable to identify any $A l u$ element that linked Tarsius to any other group, despite having characterized 16 anthropoid-specific loci and 4 Strepsirnini-specific loci. Even so, a combination of loci (showing the pre-integration site allele) and one independent insertion (showing the same fragment size as found for the filled allele of lemuriformes) suffices to generate a tentative identification of Tarsius. For studies involving the Tarsiformes, researchers may wish to refer to Schmitz et al. (2001) for three additional loci which can be used to identify Tarsius, but are not restricted to that genus.

\section{Discussion}

Prior to any project, it is crucial that a researcher be certain of the identity of the organism from which the samples were taken; unless there is definitive proof of identity (e.g., documented provenance, geographic origin, or morphological characteristics), molecular methods are required. This issue is becoming ever more prominent as researchers turn to non-invasive methods (e.g., hair or fecal samples) for obtaining molecular data (Kohn et al., 1995; Taberlet et al., 1997; Lathuilliere et al., 2001; Matsubara et al., 2005). Further, the conclusions of any project can be negatively affected if the samples used have been contaminated or inadvertently switched with DNA from other species. Finally, the identity of products seized from the illegal wildlife trade may be ambiguous without resorting to molecular markers (Hsieh et al., 2003; Yan et al., 2005; Domingo-Roura et al., 2006). The ability to determine the authentic identity of those products, even if only to the genus level or higher, is crucial to criminal investigations or to determining the likelihood of the products containing diseases representing a threat to human populations (for a discussion of disease issues with respect to primates, see Wolfe et al., 2005). The SINEs (i.e., Alu elements) comprising this demonstration dataset are valuable tools in these respects, and even the 'limitation' that Alu elements are primate-specific could be beneficial in some cases. For example, the detection of Alu elements in fecal samples from non-primate carnivores would identify particular primates as part of that animal's diet.

\subsection{Rationale for a SINE-based dichotomous key}

Several factors make a SINE-based dichotomous key valuable for identifying samples. First, genotyping SINEs requires only a PCR machine, agarose gel electrophoresis equipment, and a means of gel documentation. Second, the technique is robust even in the hands of a novice. Third, analyses are simplified by the fact that the data consist solely of the presence of either a 'filled' site (i.e., SINE present) or an 'empty' site (i.e., SINE absent) fragment for each locus. As a result, detection of these mobile elements at a series of loci can be used in a hierarchical fashion to rapidly narrow the possibilities regarding the identity of anonymous primate DNA samples (Fig. 2). Fourth, 'universal' primers are used in a simple PCR assay to amplify loci from most relevant taxa. By contrast, the mtDNA barcoding approach of IPBIR requires taxon-specific primers and procedures for eliminating the amplification of numtDNA (Lorenz et al., 2005). Finally, unlike 'single locus' (e.g., mainly mtDNA) systems, a SINE-based dichotomous key identifies organisms on the basis of multiple loci and there is no a priori reason to expect such loci to be evolutionarily linked.

SINEs are also useful characters for identifying organisms because their precise removal is extremely rare (Van de Lagemaat et al., 2005), and larger deletions that also remove a particular SINE are very unlikely to happen in multiple genomes. Thus, mobile elements are generally considered to be homoplasy-free characters (Perna et al., 1992; Hamdi et al., 1999; Batzer and Deininger, 2002; Roy-Engel et al., 2002; Salem et al., 2003b; Shedlock et al., 2004; Salem et al., 2005; Ray et al., in press). In other words, SINEs detected at a particular locus, unlike the more uncertain status of DNA sequence data, are known to be identical by descent rather than just identical by state. Further, the mode of SINE evolution is essentially unidirectional, making absence of the SINE the ancestral state for any genomic locus under consideration. Occasionally, independent insertions of SINEs in similar genomic locations will cause evolutionarily distant species to generate nearly identical DNA fragments following gel electrophoresis. DNA sequence analysis ultimately resolves these types of ambiguous loci (Salem et al., 2003a,b; Ray et al., 2005b; Xing et al., 2005; Ray et al., in press). When developing a dichotomous key, the simplest solution is to exclude ambiguous loci from consideration. When such loci are essential, additional loci from deeper within the tree can be used to identify the broader clade to which the organism belongs, thereby restricting the identification to one of the two branches characterized by the insertion. 


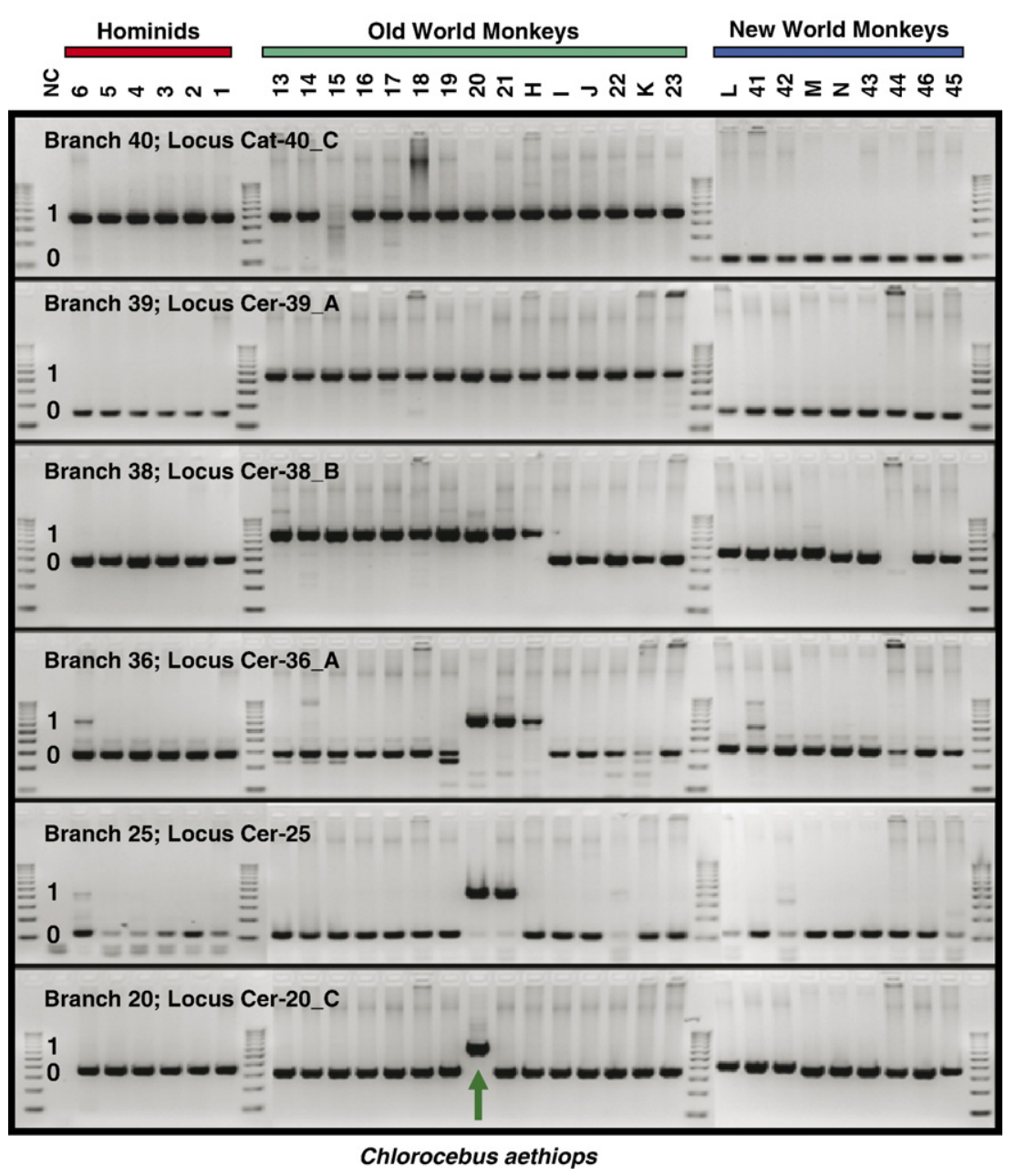

Fig. 2. Agarose gel $(2 \%)$ chromatographs demonstrating the power of the SINE-based dichotomous key approach. All 30 species, including the 'target' DNA (Chlorocebus aethiops, Green monkey), were known to be anthropoid primates; thus, loci were successively amplified from the following branches: 40 vs. 54 ; 12 vs. $39 ; 34$ vs. $38 ; 36$ vs. $37 ; 18$ vs. 25 ; and, 19 vs. 20 . Results are shown only for six loci that harbored $A l u$ insertions in the 'target' DNA, and demonstrate the range of band intensities and data quality of all loci included in the overall key. Species designations (below colored bars) are keyed to Fig. 1. Alu present ('filled' site), 1; Alu absent ('empty' site), 0. Molecular ladder ranges from 100 bp to $1000 \mathrm{bp}$, by $100 \mathrm{bp}$ increments. NC, negative water control.

\subsection{Development considerations}

The development of a SINE-based dichotomous key for identifying organisms must begin with the discovery of loci which will characterize branches in the reference phylogenetic tree. The process can be simplified by restricting primer testing to those that are either (1) designed from multiple species alignments or (2) taken from projects in which the breadth of species included in those projects inherently screened out primers with more restricted specificity. As occurred in this study for 10 terminal branches, primers designed from genome databases can generate species-specific loci; however, some loci may be shared by species related to the sequenced species that were not included in the studied taxonomic panel. Further, in some cases, loci developed from genomic databases will not be useful because the SINE elements exist at low polymorphism levels within the species or are even restricted to the sequenced individual; about $5 \%$ of the new loci developed for this analysis had to be discarded for these reasons. Finally, when sequence data are not available, species-specific loci must be generated through techniques such as PCR-display (Roy et al., 1999; Sheen et al., 2000; Badge et al., 2003; Biedler et al., 2003; Okada et al., 2004; Ray et al., 2005b; Xing et al., 2005).

With the possible exception of terminal branches, each node of a robust SINE-based dichotomous key will have two primer sets, each one amplifying different SINE elements and identifying one of the bifurcations. Ideally, the key will also consist almost exclusively of loci that produce clearly empty alleles from organisms which are not supposed to harbor the SINE insert; as a result, if the analysis is started in the wrong part of the tree, the process will self-correct because all primer pairs will generate only 'empty' site fragments (Fig. 3). This allows the key to be used at multiple levels, depending on the researcher's needs. If absolutely nothing is certain about the sample's identity, the analysis should begin at the deepest node of the tree (i.e., with loci from Branches 55 and 73) and work toward the terminal branches. At each bifurcation in the tree, Alu elements in the sample DNA will be detected within loci from one of the two branches, directing the analysis to the next bifurcation along that branch (Figs. 1-3). On the other hand, 

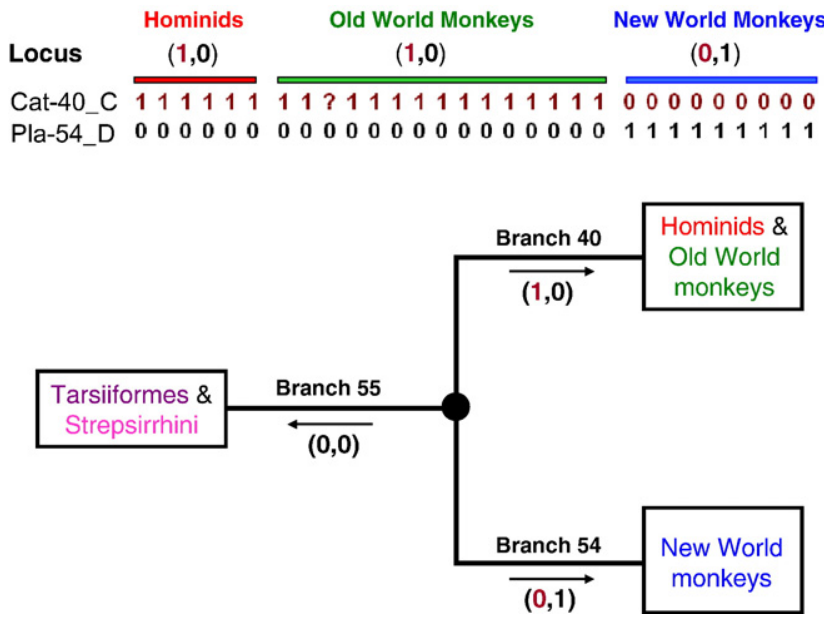

Fig. 3. Example of data and decision key. At each bifurcation in the tree, one set of primers detects $A l u$ insertions in species downstream from the top branch and a second set of primers detects different Alu insertions in species associated with the bottom branch. Thus, if the analysis begins at an internal branch (see Fig. 2) with one locus from the top branch (e.g., Cat-40_C) and one locus from the bottom branch (e.g., Pla-54-D), the result can be: 1,0 (analysis proceeds down Branch 40); 0,1 (analysis proceeds down Branch 54); or 0,0 (which indicates the analysis began in the wrong part of the tree). Alu present, $1 ; A l u$ absent, 0 ; No amplification or multiple, weakly amplifying fragments, ?

validated information about the sample beyond the scope of the key can justify bypassing the deepest nodes. At the most extreme, for cell cultures involving a set number of species, using only loci from close to the terminal branches is entirely appropriate. Further, to some extent, the identity of a primate can be ascertained by knowing the world region from which it came. For instance, lemuriformes are restricted to Madagascar; the NWM genera are found only in Central and South America; and (with the exception of the world-wide distribution of Homo sapiens) all other primates share varying degrees of overlap in Africa and Asia (Disotell, 2003). Thus, for a primate sample taken from Central or South America, it would be reasonable to begin the analysis within the Platyrrhini clade (i.e., with loci from Branches 47 and 53).

\subsection{Analysis considerations}

When analyzing data in the context of a dichotomous SINEbased key, it is critical that the evaluator keeps several issues in mind regarding the key's characteristics (for a general discussion of interpreting SINE data, see Shedlock et al., 2004). (1) If the key is based on an organismally-restricted SINE family, using it to analyze DNA samples from organisms outside of that organismal group will be uninformative at best. (2) In most cases, the dichotomous key is likely to have been based on a single specimen for each terminal branch (as occurred in this demonstration project); therefore, terminal branch loci might be polymorphic with respect to presence or absence of the SINE element. If true, then some individuals belonging to that terminal branch will show an empty site rather than a filled site for that locus. This means that, while data for deeper nodes of the tree will apply to all relevant organisms, amplification of a single allele (either null or filled) at a terminal branch is not definitive. Nevertheless, if multiple loci are examined (from the terminal branch and preceding branches), the overall pattern of results will be definitive. (3) Closely related (but not analyzed during the key's construction) species may or may not have the SINE element. As such, for a truly anonymous DNA sample, any match to a terminal branch can only be considered as being consistent with that identity rather than as being a positive identification. Of course, the identification might be clarified by other factors which further narrow the possibilities (e.g., the sample's geographic origin). (4) For any single locus, an individual specimen can generate an aberrant and misleading PCR product. (5) Some SINE elements are truncated, leading to less than the typical size difference (for that family of SINEs) between the empty and filled site fragments. Further, predicted fragment sizes may not be realized in some species (or individuals) because of deletions or insertions nearby the SINE element (but within the primer sites) or even within the SINE element itself.

\subsection{Recommendations for use of the dichotomous key}

To guard against the above concerns, we strongly recommend that multiple loci be used in any identification. For this dichotomous Alu-based key, we have typically provided at least six loci (three for each branch) at each node to facilitate this process. In addition, running known controls (for the empty and filled site fragment sizes) concurrently with anonymous DNA samples will facilitate band sizing. If certain loci will be used routinely, it may be useful to optimize primer designs or PCR protocols to generate cleaner bands and to eliminate PCR dropouts. Typical optimization procedures may include designing new primers based on current sequence databases, adjustments to annealing temperatures or times, and reductions in the number of PCR cycles. These types of adjustments were used to create the current dataset; however, the goal was to generate useful PCR products from as many species as possible, which means that the current conditions are sometimes suboptimal for particular clades within the phylogenetic tree. Thus, when electrophoresing the entire PCR product, band intensities ranged from very weak to extremely strong (sometimes also displaying extraneous, weakly amplifying PCR products). Details on these issues and additional potentially useful loci can be found in Supplemental Table 1 on our website (http://batzerlab.lsu.edu) under publications. Finally, given that our dataset included 56 species, it was impractical to determine locus-specific population insertion polymorphism levels for each species; however, such testing (at least with terminal branch loci) would be immensely beneficial for anyone working with a smaller subset of species.

\section{Conclusion}

Because Alu elements are restricted to the primate lineage, this particular dataset can only be applied to primate DNA. Nevertheless, the general principle of using SINEs and other transposable elements to identify organisms is broadly applicable, and the newly emerging genome databases will facilitate finding informative loci based on other elements. For example, 
the genomic scaffolds for Target 1 are already available for at least 34 species (ranging from fish and amphibians to birds and reptiles to marsupials, rodents, primates and other mammals). In the human, Target 1 represents $\sim 1.9 \mathrm{Mb}$, and this region is a rich source for many different families of SINEs. Further, a computer software now exists that can process multiple species alignments of those genomic scaffolds. Finally, in this demonstration project, we used a single SINE family ( $A l u$ elements) to characterize informative loci; the future development of dichotomous SINE-based keys for other groups of organisms will be simplified by including a mix of SINE families.

\section{Acknowledgments}

We thank Drs. L. Chemnick, T. Disotell, O. Ryder, and C.-B. Stewart for providing DNA samples. This research was supported by the National Science Foundation grants BCS0218338 and EPS-0346411 and by the State of Louisiana Board of Regents Support Fund (to M.A.B.). Jacquelyn Zimmerman was supported by a Howard Hughes Medical Institute grant to Louisiana State University through the Undergraduate Biological Sciences Education program.

\section{Appendix A. DNA samples of all species included in this SINE-based dichotomous key}

\begin{tabular}{|c|c|c|c|}
\hline Species names & Common names & Origin & ID number \\
\hline \multicolumn{4}{|l|}{ Hominids (5 genera; 8 species) } \\
\hline Gorilla gorilla & Lowland gorilla & Coriell $^{\mathrm{a}}$ & $\mathrm{AG} 05251^{\mathrm{b}}$ \\
\hline Homo sapiens & Human & Roche $^{\mathrm{c}}$ & 1691112 \\
\hline Pan paniscus & Bonobo & IPBIR $^{\mathrm{d}}$ & PR00661 ${ }^{\mathrm{b}}$ \\
\hline Pan troglodytes & $\begin{array}{l}\text { Common chimpanzee } \\
\text { ('Clint') }\end{array}$ & IPBIR & NS06006 ${ }^{\mathrm{b}}$ \\
\hline Hylobates gabriellae & $\begin{array}{l}\text { Buff (or red) cheeked } \\
\text { gibbon }\end{array}$ & IPBIR & PR00652 \\
\hline Hylobates lar & White-handed gibbon & IPBIR & PR00715 \\
\hline $\begin{array}{l}\text { Hylobates syndactylus } \\
\text { syndactylus }\end{array}$ & Siamang & IPBIR & PR00598 \\
\hline Pongo pygmaeus & Sumatran orangutan & Coriell & GM06213A ${ }^{b}$ \\
\hline \multicolumn{4}{|c|}{ Old World Monkeys (16 genera; 21 species) } \\
\hline Allenopithecus nigroviridis & Allen's swamp monkey & IPBIR & PR00198 \\
\hline Cercocebus agilis & Agile mangabey & Disotell $^{\mathrm{e}}$ & N/A \\
\hline Cercopithecus lhoesti & L'Hoest's monkey & IPBIR & PR00283 \\
\hline Cercopithecus wolfi wolfi & Wolf's guenon & IPBIR & PR00486 \\
\hline Chlorocebus aethiops & African green monkey & $\operatorname{ATCC}^{f}$ & CCL70 ${ }^{\mathrm{b}}$ \\
\hline Colobus guereza kikuyuensis & Kikuyu colobus & SDFZ $^{\mathrm{g}}$ & OR 160 \\
\hline Erythrocebus patas & Patas monkey & SDFZ & KB5435 \\
\hline Lophocebus aterimus & Mangabey & Disotell & G139 \\
\hline Macaca nemestrina & Pigtailed macaque & Coriell & NG08452 \\
\hline Macaca silenus & Lion-tailed macaque & SDFZ & OR 1890 \\
\hline Macaca mulatta & Rhesus macaque & Coriell & NG07109A \\
\hline Mandrillus sphinx & Mandrill & Disotell & 1148 \\
\hline Miopithecus talapoin & Talapoin & SDFZ & OR 755 \\
\hline Nasalis larvatus & Proboscis monkey & Stewart ${ }^{\mathrm{h}}$ & N/A \\
\hline Papio cynocephalus & Yellow baboon & SFBR $^{\mathrm{i}}$ & 9656 \\
\hline Papio anubis & Olive baboon & SFBR & 8229 \\
\hline Pygathrix nemaeus & Douc langur & SDFZ & OR 259 \\
\hline $\begin{array}{l}\text { Semnopithecus entellus } \\
\text { entellus }\end{array}$ & Hanuman langur & IPBIR & PR00739 \\
\hline Theropithecus gelada & Gelada baboon & SDFZ & KB 10538 \\
\hline
\end{tabular}

Appendix A (continued)

\begin{tabular}{|c|c|c|c|}
\hline Species names & Common names & Origin & ID number \\
\hline \multicolumn{4}{|c|}{ Old World Monkeys (16 genera; 21 species) } \\
\hline Trachypithecus cristatus & Silvered leaf langur & SDFZ & B 4381 \\
\hline $\begin{array}{l}\text { Trachypithecus vetulus } \\
\text { nestor }\end{array}$ & $\begin{array}{l}\text { Western purple-faced } \\
\text { langur }\end{array}$ & SDFZ & OR 219 \\
\hline
\end{tabular}

New World Monkeys (9 genera; 11 species)

\begin{tabular}{|c|c|c|c|}
\hline Alouatta sara & $\begin{array}{l}\text { Bolivian red howler } \\
\text { monkey }\end{array}$ & SDFZ & OR 749 \\
\hline Aotus trivirgatus & $\begin{array}{l}\text { Three-striped owl } \\
\text { monkey }\end{array}$ & ATCC & CRL1556 \\
\hline Ateles belzebuth & Spider monkey & SDFZ & KB 6701 \\
\hline Ateles geoffroyi & Spider monkey & Coriell & $\mathrm{AG} 05352^{\mathrm{b}}$ \\
\hline $\begin{array}{l}\text { Callicebus } d . \\
\quad \text { donacophilus }\end{array}$ & Bolivian gray titi & SDFZ & OR 1522 \\
\hline Callithrix pygmaea & Pygmy marmoset & SDFZ & OR 690 \\
\hline Lagothrix lagotricha & $\begin{array}{l}\text { Common woolly } \\
\text { monkey }\end{array}$ & Coriell & AG05356 \\
\hline Pithecia p. pithecia & $\begin{array}{l}\text { Northern white-faced } \\
\text { saki }\end{array}$ & SDFZ & OR 842 \\
\hline $\begin{array}{l}\text { Saguinus fuscicollis } \\
\text { nigrifrons }\end{array}$ & $\begin{array}{l}\text { Geoffroy's } \\
\text { saddle-back tarmarin }\end{array}$ & SDFZ & OR 621 \\
\hline Saguinus labiatus & $\begin{array}{l}\text { Red-chested } \\
\text { mustached tamarin }\end{array}$ & Coriell & NG05308 \\
\hline Saimiri s. sciureus & Squirrel monkey & SDFZ & KB 4544 \\
\hline
\end{tabular}

Strepsirrhini and Tarsier (12 genera; 16 species)

Daubentonia

madagascariensis

Eulemur fulvus albifrons

Aye-aye

IPBIR PR00794

IPBIR PR01017

Eulemur macaco

Galago moholi

Brown (white-fronted) IPBIR PR00245

lemur

Galago senegalensis

Black lemur

IPBIR PR00266

Southern lesser IPBIR PR01035

Hapalemur griseus griseus

bushbaby

Lesser (Senegal)

bushbaby

Microcebus murinus

Bamboo (gray gentle) lemur

Lemur catta

Mirza coquereli

Gray mouse lemur

Ring-tailed lemur

Coquerel's mouse

lemur

Nycticebus coucang

bengalensis

Nycticebus pygmaeus

Otolemur garnettii

Tarsius bancanus

Tarsius syrichta

Bengal slow loris

Batzer $^{\mathrm{j}} \quad \mathrm{N} / \mathrm{A}$

Varecia variegata ruber

Pygmy loris

Garnett's galago

Western tarsier

Philippine tarsier

Red ruffed lemur

IPBIR PR00257

SDFZ KB6993

Coriell NG07099

IPBIR PR00871

a Coriell: Coriell Institute for Medical Research, 403 Haddon Avenue, Camden, NJ 08103.

${ }^{\mathrm{b}}$ Genomic DNA derived from cell lines. All others (except Human) were derived from whole genome pre-amplification using the Genomiphi genome amplification kit (Amersham, Sunnyvale, CA).

${ }^{c}$ Roche: www.roche-applied-science.com; high molecular weight genomic DNA (blood).

d IPBIR: Integrated Primate Biomaterials and Information Resource (Coriell).

e Disotell: Blood sample from Dr. Todd Disotell.

${ }^{f}$ ATCC: Cell lines, American Type Culture Collection, P.O. Box 1549, Manassas, VA 20108.

g SDFZ: Frozen Zoo, San Diego Zoo, conservationandscience.org.

${ }^{\text {h }}$ Stewart: DNA sample from Dr. Caro-Beth Stewart.

${ }^{i}$ SFBR: Southwest Foundation for Biomedical Research.

${ }^{\mathrm{j}}$ Batzer: Adenovirus 12 SV40-transformed fibroblasts maintained in lab of Dr. Mark Batzer. 
Appendix B. Branch-specific loci for a dichotomous SINE-based (i.e., Alu) primate identification key

\begin{tabular}{|c|c|c|c|c|c|c|}
\hline Primer $^{a}$ & $\mathrm{AT}^{\mathrm{b}}$ & Fill $^{\mathrm{c}}$ & Null & Forward primer $\left(5^{\prime}-3^{\prime}\right)$ & Reverse primer $\left(5^{\prime}-3^{\prime}\right)$ & Atypical amplification $^{\mathrm{d}}$ \\
\hline Hom-1_A & 60 & 670 & 370 & ggttttctcaagcctttcaac & tctacaccaaggccaagctc & $M \cdot 42 \cdot 56 \cdot 64 \cdot 65^{i} \cdot 66$ \\
\hline Hom-1_B & 60 & 920 & 620 & gtagaacatttcaagtctgtagtgaag & aaaagcctgaagtttggaatc & $\mathrm{D} \cdot 41 \cdot 45 \cdot 56 \cdot 73$ \\
\hline Hom-1_C & 63 & 570 & 270 & aactaccttgtgtgtsaatgtttg & cagccagagagcatcagtttc & $P \cdot 17 \cdot 29 \cdot 73$ \\
\hline Hom-2_A & 55 & 560 & 240 & gcatgtggaacatttaccaaga & cagctcaaaatagcttctaatttcc & $\mathrm{F} \cdot 14 \cdot 18 \cdot 54$ \\
\hline Hom-2_B & 55 & 830 & 510 & cccagattgattcttccettta & atgccagttccattatttccac & $\mathrm{C}^{\mathbf{d}} \cdot \mathrm{L} \cdot \mathrm{P}^{\mathbf{d}} \cdot 45$ \\
\hline Hom-3 & 55 & 590 & 280 & gatgtccattgctttgcagt & gaaagaggcagattcaaagcat & $\mathrm{H} \cdot \mathrm{J} \cdot \mathrm{K} \cdot 18 \cdot 19 \cdot 34 \cdot 42 \cdot 43 \cdot 47$ \\
\hline Hom-4_A & 55 & 530 & 210 & aattctttggggtaggtggaat & cacaacgtacaccctaaaatgg & 42 \\
\hline Hom-4_B & 60 & 780 & 480 & ttccttgctaaagagagaagtgg & tctccaggaagatgecctac & 73 \\
\hline Hom-4_C & 63 & 550 & 190 & atcacactgctgcctcaaac & gcaagagaggttgggaaatg & $43 \cdot 44 \cdot 45$ \\
\hline Hom-5_A & 60 & 1000 & 700 & cagaaacaayggtaagggaggag & tccacaagtacaactasattgagagg & $\mathrm{P} \cdot 21^{\mathrm{Alu}}$ \\
\hline Hom-5_B & 60 & 750 & 450 & tcgactgatgcagattytcttag & agttgtctttctacttcctcataaytg & 49 \\
\hline Hom-5_C & 60 & 1200 & 900 & tcacttaagcccrggaggtc & tttccccttgtaagattttatgc & $A \cdot 6^{\mathbf{i}} \cdot 18 \cdot 27 \cdot 54$ \\
\hline Hom-6 & 60 & 600 & 250 & cctagatgcaaatcctgaatatc & ccaaacyaagtagccactgga & $\mathrm{B} \cdot \mathrm{J} \cdot \mathrm{P} \cdot 42 \cdot 49^{\mathrm{i}}$ \\
\hline Hom-7_A & 59 & 620 & 300 & cacaatttcatttccaatcca & ttgcccaaatgtagaatgtgac & $\mathrm{D} \cdot 16 \cdot 18 \cdot 29 \cdot 54$ \\
\hline Hom-7_B & 58 & 720 & 420 & gtctcttctgtgccaaaataatg & ttctaagttaattctgtctaggacctc & $X^{\text {Alu }} \cdot P \cdot 20 \cdot 61 \cdot 63 \cdot 64$ \\
\hline Hom-7_C & 60 & 1030 & 740 & tgtgagctttcttgggatgaag & cacatatatttctttgctctgtcagc & $45 \cdot 51 \cdot 73$ \\
\hline Hom-7_D & 60 & 500 & 180 & cagaaatgagtacagagectcac & ttgctccttctattattccatcag & $41 \cdot 45 \cdot 73$ \\
\hline Hom-8_A & 55 & 650 & 350 & ctgaagartggcaggaaacc & cacrtaaatttggagtagtgaatc & $\mathrm{H}^{\mathrm{Alu}} \cdot 44$ \\
\hline Hom-8_B & 55 & 600 & 250 & tcctcacttgectaattttctttg & gtgtccaagaagagcaagaaatc & $P \cdot 46 \cdot 73$ \\
\hline Hom-8_C & 58 & 350 & 180 & cttaggaaagagggaaaagi & cagtaggaaaatgaagcaatc & $14 \cdot 73$ \\
\hline Hom-8_D & 60 & 500 & 180 & tctccetcagctaggtcatc & tttgacatctatttggaagc & $\mathrm{J} \cdot \mathrm{K} \cdot 22 \cdot 41$ \\
\hline Hom-8_E & 60 & 700 & 390 & acttattttagcatccectatgc & tttggcasacttagakgaaagac & $42 \cdot 48$ \\
\hline Hom-9_A & 55 & 450 & 150 & tacctgtaccegtatttcattcct & tgttctagtggtattgtgggttttt & $\mathrm{C}^{\mathrm{Alu}} \cdot \mathrm{P} \cdot 4 \cdot 42 \cdot 46^{\mathrm{i}} \cdot 47$ \\
\hline Hom-9_B & 55 & 680 & 380 & cctcaggattctactactggtt & gttcaactctttgccacatc & $13 \cdot 14 \cdot 17 \cdot 24 \cdot 44 \cdot 46$ \\
\hline Hom-9_C & 60 & 810 & 510 & atcgactaatggcatcctcct & ctctcccagaaagactgaaaggt & $\mathrm{P} \cdot 17 \cdot 43^{\mathrm{i}} \cdot 44^{\mathrm{d}} \cdot 45 \cdot 46^{\mathrm{i}} \cdot 47$ \\
\hline Hom-10_A & 55 & 430 & 120 & tgccagacacatcatctaag & cattcctggaaaatttagtg & $\mathrm{G}^{\text {Alu }} \cdot 32^{\text {Alu }}$ \\
\hline Hom-10_B & 55 & 510 & 180 & gtgaatgcagatcattatggaaag & gggaaaagatgcagtgtagagttt & $44^{\mathrm{i}}$ \\
\hline Hom-10_C & 60 & 430 & 120 & atgecattttatccacaact & cacccagaaatttggtaact & $\mathrm{P} \cdot 13 \cdot 17$ \\
\hline Hom-10_D & 60 & 470 & 150 & taaatgtttccetggataacceta & gaaaacgaagtgctcattcagtaa & $\mathrm{C} \cdot \mathrm{M} \cdot 18 \cdot 21 \cdot 27 \cdot 45 \cdot 47$ \\
\hline Hom-11_A & 55 & 490 & 180 & agagatatggeatccettta & ggaagatattattgggcaaa & $\mathrm{L} \cdot \mathrm{M} \cdot \mathrm{P} \cdot 42 \cdot 44 \cdot 46$ \\
\hline Hom-11_B & 55 & 810 & 550 & ctccetcecetcectttg & cacctcagattcaaaccaaaac & 73 \\
\hline Hom-11_C & 60 & 410 & 300 & ccccagtcccctatagaagataat & tcaaacaaactgggatacttctga & $\mathrm{M} \cdot \mathrm{N} \cdot \mathrm{P} \cdot 42$ \\
\hline Hom-12_A & 55 & 430 & 130 & gttattttgaaggcttgctg & tacgggcttacagtgaattt & $L \cdot 16 \cdot 44$ \\
\hline Hom-12_B & 55 & 460 & 130 & tagatagcagecccattcca & cctttcgacacgggaaagta & 45 \\
\hline Hom-12_C & 55 & 500 & 190 & acatttcgettgtccetttc & caaagaaacggacgttgcac & $\mathrm{H} \cdot 15^{\mathrm{i}}$ \\
\hline Hom-12_D & 55 & 470 & 160 & ccagaggctattgatgtagc & cattttgtctactccettgc & 42 \\
\hline Hom-12_E & 55 & 500 & 200 & tgtctcttcaaagttgtttctctg & tttatcatagccagccctttc & $\mathrm{W} \cdot 56 \cdot 63 \cdot 66$ \\
\hline Hom-12_F & 55 & 760 & 430 & ggtggctggarttttgcac & gcaagaatgccatagcctagc & $\mathrm{L} \cdot 42 \cdot 44 \cdot 73$ \\
\hline Hom-12_G & 55 & 960 & 660 & cctactacaaaggccaagcaag & ttctgcttttatgcttcagctc & $18 \cdot 44 \cdot 73$ \\
\hline Hom-12_H & 55 & 570 & 270 & cctaccttctgttttaatcactgg & gccaaatttttatccaaaygaa & $42 \cdot 73$ \\
\hline Hom-12_I & 55 & 500 & 180 & gtttaataacctttctcctttgg & aatacagctgacccwggaatg & None \\
\hline Cer-13 & 60 & 600 & 250 & tgcacatcaggcactttctg & tgtttttgaaaagagcacaacc & $O \cdot P \cdot 45$ \\
\hline Cer-14_A & 50 & 680 & 370 & tctgctgtagatcgctcacaat & ctccecacccetgatttattac & $14^{\mathbf{E F}} \cdot 22$ \\
\hline Cer-14_B & 51 & 570 & 260 & tgtttgctctgaccaattcc & caaccaacggectatcaagt & $P \cdot 15 \cdot 44 \cdot 47 \cdot 51$ \\
\hline Cer-14_C & 53 & 670 & 360 & cgttctcatcacactgtggttc & attgctaccgagttccaaagaa & $\mathrm{M} \cdot \mathrm{O} \cdot \mathrm{P} \cdot 43$ \\
\hline Cer-15_A & 55 & 650 & 340 & ttatgggcccaatttaagtttt & ataaaatggacttgccagatgc & $A^{\text {H. syn }} \cdot P$ \\
\hline Cer-15_B & 55 & 610 & 350 & tgctcccatttatgaggatttt & atggggttgtctgtctgtctct & None \\
\hline Cer-15_C & 55 & 630 & 320 & cagttaggtggcttagggaaaa & tcctattggcattaaagcatga & None \\
\hline Cer-16_A & 50 & 450 & 140 & caatcaatgcgataacaatgg & agtgggcagtaggaacaaggt & $\mathrm{F} \cdot \mathrm{K} \cdot 13 \cdot 14 \cdot 16 \cdot 17 \cdot 18 \cdot 47 \cdot 49 \cdot 50$ \\
\hline Cer-16_B & 55 & 450 & 140 & aagggetgtatgccgttttat & aggactgacaacctggtattaagaa & $\mathrm{E}^{\mathbf{E F}} \cdot \mathrm{G} \cdot 4 \cdot 54$ \\
\hline Cer-16_C & 55 & 490 & 180 & gtcagtatttgccaagttgtgg & ttggttatcctccaaaaagtgc & 2 \\
\hline Cer-17_A & 50 & 460 & 170 & tctcccaacatcctcaaacac & ccacttcccaaaccatgataa & $A^{\text {H. lar. }} \cdot P \cdot 17^{\mathbf{E F}} \cdot 49$ \\
\hline Cer-17_B & 52 & 520 & 210 & tatgtcttagggetgcaaatcc & tgttaaaagtgcggttctcaaa & $C \cdot P \cdot 25 \cdot 49 \cdot 46$ \\
\hline Cer-17_C & 55 & 490 & 180 & tccttaaggctaatgcaaggac & cctccatacacagtggtaagaaaa & $42 \cdot 50$ \\
\hline Cer-18_A & 55 & 570 & 260 & gcctggttcacagtttggtaa & ttgtcaaggagtggggaaata & $\mathrm{F} \cdot \mathrm{H} \cdot \mathrm{K} \cdot 16 \cdot 54$ \\
\hline Cer-18_B & 55 & 600 & 280 & gaatccaatgaaacccagtg & aagccataccaccagaccac & 44 \\
\hline Cer-19_A & 50 & 600 & 300 & tcctctgagctggcacatatt & cetgctagccattcacaagtt & None \\
\hline Cer-19_B & 55 & 660 & 350 & tcaggatagtgcttgcctcat & tgatgccatagcaataaaaagg & 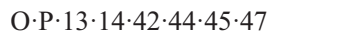 \\
\hline Cer-20_A & 53 & 520 & 210 & ctggacactggtggaagaaaa & cagagaacccgttttgtgag & $\mathrm{P} \cdot 8 \cdot 14$ \\
\hline Cer-20_B & 56 & 900 & 700 & acaaaagttktgggtgcttc & aaagttgttttctccctaraagg & None \\
\hline Cer-20_C & 60 & 750 & 400 & cacaaaatactaaaggactgttaaagg & ggaaatcttatgagagaggagagc & None \\
\hline Cer-21_A & 50 & 600 & 290 & ttccaagtgtggaaattggtag & tcatcttgaaacaggaatacgg & $P \cdot 6 \cdot 42$ \\
\hline
\end{tabular}


Appendix B (continued)

\begin{tabular}{|c|c|c|c|c|c|c|}
\hline Primer $^{\mathrm{a}}$ & $\mathrm{AT}^{\mathrm{b}}$ & Fill $^{\mathrm{c}}$ & Null & Forward primer $\left(5^{\prime}-3^{\prime}\right)$ & Reverse primer $\left(5^{\prime}-3^{\prime}\right)$ & Atypical amplification ${ }^{\mathrm{d}}$ \\
\hline Cer-21_B & 60 & 560 & 250 & gcttcaaattggtcaacaacct & taaacaaggggaaaggctatga & $\mathrm{P}$ \\
\hline Cer-21_C & 60 & 620 & 260 & agagggacttggacatgcttt & tggggttaaatgattaaatggtg & $\mathrm{O}$ \\
\hline Cer-21_D & 55 & 950 & 700 & tgttgccaaaattgtcttacctc & aatatgttgctgecaatcacc & $\mathrm{H}^{\mathbf{E F}} \cdot 54$ \\
\hline Cer-22_B & 60 & 700 & 390 & tccagtgaacagtttgcttcaa & tcagccccatgggatatagtag & $\mathrm{G} \cdot 5 \cdot 54$ \\
\hline Cer-22_C & 60 & 500 & 210 & tctgtctctggtacgtcaggaa & taagattactgtgcagccetga & 54 \\
\hline Cer-23_A & 55 & 520 & 210 & taaatcaggactgttcccaagg & cactaggctccacatgacagag & 42 \\
\hline Cer-24_B & 56 & 560 & 230 & ctcaagcttctccectcetta & aaggcacaggattctgctttt & $C \cdot P \cdot 42 \cdot 46$ \\
\hline Cer-24_C & 60 & 550 & 240 & tgccaggagaaaacttaaatga & ttaaggggaggaagtagggaag & $\mathrm{P} \cdot 24^{\mathrm{EF}} \cdot 42 \cdot 44 \cdot 45 \cdot 46 \cdot 47 \cdot 48$ \\
\hline Cer-25 & 60 & 460 & 110 & cttcctagggetgctatgacaa & gagagaacatggcettgctaat & $\mathrm{C}^{\text {Alu }} \cdot \mathrm{D}^{\mathrm{EF}}$ \\
\hline Cer-26 & 55 & 520 & 210 & ttttgaacaagagaccccata & agccagataatatccetgttgc & 41 \\
\hline Cer-27_A & 60 & 700 & 380 & tctaaggcagccattgagtg & ccaggtttgcetctgactcc & 46 \\
\hline Cer-27_B & 60 & 500 & 180 & agctaatatgtcaaggctsctg & cttggcetgatgtgtgtttayag & $\mathrm{A}^{\text {H. lars }} \cdot 41$ \\
\hline Cer-29_C & 57 & 560 & 250 & tgccaaaaactcaggttaagaga & atttgggggaaaactgctatc & $42 \cdot 45 \cdot 47$ \\
\hline Cer-30_A & 55 & 640 & 320 & atttggtcatctgtcactgcat & agattaggataaacccccaagg & $A^{\text {H. lars }} \cdot E^{\mathbf{E F}} \cdot P \cdot 19^{\mathbf{E F}}$ \\
\hline Cer-30_B & 57 & 630 & 410 & tggcaggatccactcagtagta & taccttttgttgtgectttcet & $\mathrm{P} \cdot 17 \cdot 41^{\mathrm{d}}$ \\
\hline Cer-31_A & 57 & 520 & 210 & caaccaacagaataggggaaaa & ttcttcatgatattgcctttgc & $\mathrm{C}^{\mathrm{Alu}} \cdot \mathrm{O} \cdot \mathrm{P}$ \\
\hline Cer-31_B & 55 & 700 & 400 & aaggcactggggaatacaaag & ttaaatcattgctgtccttttgc & $D^{\mathbf{d}} \cdot F \cdot 18^{\mathbf{d}} \cdot 54$ \\
\hline Cer-32_A & 55 & 540 & 230 & ggctccetctccettagactac & taccaggaatgtttggaaatgg & $P \cdot 42$ \\
\hline Cer-32_B & 57 & 580 & 270 & ctctcagctcectgtttctgtt & catggacatcagactagccact & $\mathrm{P}$ \\
\hline Cer-32_C & 58 & 530 & 200 & tatcaagagcaatctttcaattatg & accatatgggctcagtctgc & $5^{i} \cdot 44$ \\
\hline Cer-33_A & 55 & 530 & 220 & acagggatttcagagcacaagt & cagctcattattcccaaacaca & None \\
\hline Cer-33_B & 55 & 620 & 310 & ttttgtaaacagccaaagctca & ttgttgaaaatatggcacaagc & $\mathrm{P}$ \\
\hline Cer-33_C & 55 & 560 & 250 & ttctaagcaggacctaaaaagca & tcatttcagagatttgctgatg & $P \cdot 45 \cdot 51$ \\
\hline Cer-33_D & 60 & 440 & 130 & atgtgaagacctctgcccagta & tccttttgttcaaactgcttctt & $\mathrm{M} \cdot \mathrm{O} \cdot 42 \cdot 52$ \\
\hline Cer-34_A & 50 & 510 & 200 & ccaccetttcctaaatttcca & gtcttggetttccettctacg & $P \cdot 43 \cdot 47$ \\
\hline Cer-36_B & 54 & 700 & 400 & cttgttgagcatcttytgtgc & tctagttccgttgatgtaataatgc & $M \cdot P \cdot 46$ \\
\hline Cer-36_C & 63 & 900 & 700 & tggtgggctaaggagaagg & cccagaggaaagtctgaattg & $18 \cdot 54$ \\
\hline Cer-37_A & 55 & 550 & 230 & gcaacatttacaagatgctcaag & acttgggagcaaacatctcct & $\mathrm{A}^{\mathrm{H.} \mathrm{lars}} \cdot \mathrm{L} \cdot \mathrm{O} \cdot \mathrm{P}$ \\
\hline Cer-37_B & 57 & 750 & 440 & aagaagtcacaaagagggaagg & ttttgetggtggttccttaaac & $P \cdot 47$ \\
\hline Cer-37_C & 60 & 480 & 170 & ctctacttttaggggectgett & ccagacctggaaactcaagaat & None \\
\hline Cer-38_A & 55 & 490 & 170 & agcaaatcttgaagcaccagtt & gcagcaataataggtttggttca & $O \cdot P \cdot 20$ \\
\hline Cer-38_B & 60 & 720 & 410 & gtagaatgaccaaagcgaggtt & cacatcagtgggtgcctattta & 42 \\
\hline Cer-38_C & 60 & 680 & 380 & agtttggaagcagtgagtcagg & ccagtttgcaattgatttctga & $\mathrm{G} \cdot \mathrm{P} \cdot 45$ \\
\hline Cer-38_D & 53 & 550 & 250 & tcatcacagaaagtcagtgtcag & aaaggtggaaatagtcacataatc & None \\
\hline Cer-38_E & 56 & 550 & 200 & tcaaagccagtgcttattaaas & taagtggacaaggccaaagc & 54 \\
\hline Cer-38_F & 56 & 600 & 280 & aagatgtttgctgacagartatg & tctttgacagatagtgcttttattc & $\mathrm{L}^{\mathrm{i}}$ \\
\hline Cer-39_A & 50 & 470 & 160 & aaacatcagtgaaaatttgcttaca & tcacatgtatttgtgcaacacttc & $\mathrm{P}$ \\
\hline Cer-39_B & 55 & 850 & 520 & tgccataaactgaccetgacta & ggcaccaaagagaaacacatct & None \\
\hline Cer-39_C & 60 & 580 & 250 & gtgcaagtgaacatgtggctat & ccacaatttctaagagggcaag & $\mathrm{L}$ \\
\hline Cer-39_D & 60 & 790 & 450 & cagccaaaacactaaatgttgg & tcatttcagtgtcagtttgcat & $\mathrm{L} \cdot 42 \cdot 44$ \\
\hline Cer-39_E & 60 & 580 & 260 & aggactgactgagaaccagagtc & acagctccaatttcaccctaaa & $F \cdot G \cdot P \cdot 14 \cdot 18 \cdot 44$ \\
\hline Cer-39_F & 54 & 500 & 170 & tcatactttatgtgcaattttatatcc & tgctcaacaacagkaaaatg & None \\
\hline Cat-40_A & 60 & 890 & 590 & getcaccatgatctaatttcctg & ctggttctgcaatcacatcttc & 54 \\
\hline Cat-40_B & 60 & 840 & 480 & tcatgtgaggaagagcttgag & gttgtcacagcatagcagaatc & $42 \cdot 56 \cdot 73$ \\
\hline Cat-40_C & 60 & 410 & 110 & tgaatctctgagaattascaccac & aagatcaagatgctggagaatg & $15 \cdot 73$ \\
\hline Cat-40_D & 60 & 800 & 500 & cacttatactctgtggagaacyctaac & gaaaagrcccaatttgtagggaag & $A^{\text {H.syn. }} \cdot T \cdot 42 \cdot 43 \cdot 56 \cdot 59 \cdot 65$ \\
\hline Cat-40_E & 60 & 680 & 130 & tctgtcatggaagctagaagagc & ctgcccagagasggtatttactatg & $\mathrm{T} \cdot 44 \cdot 56 \cdot 60 \cdot 66$ \\
\hline Pla-41_A & 55 & 520 & 200 & gcacctacccacgaaaagaa & acattgcctctgcaaattga & $C \cdot P \cdot 51$ \\
\hline Pla-41_B & 55 & 360 & 220 & aarcttaggccagctggaaa & ggytgaggaagtggtttgga & $18 \cdot 20^{\mathbf{i}} \cdot 23^{\mathbf{i}}$ \\
\hline
\end{tabular}


Appendix B (continued)

\begin{tabular}{|c|c|c|c|c|c|c|}
\hline Primer $^{\mathrm{a}}$ & $\mathrm{AT}^{\mathrm{b}}$ & Fill $^{\mathrm{c}}$ & Null & Forward primer $\left(5^{\prime}-3^{\prime}\right)$ & Reverse primer $\left(5^{\prime}-3^{\prime}\right)$ & Atypical amplification ${ }^{\mathrm{d}}$ \\
\hline Pla-42_A & 53 & 530 & 200 & ctcagcccaacatcacagaa & cacatcatgaaatcttccttctct & $\mathrm{G} \cdot 6$ \\
\hline Pla-42_B & 59 & 490 & 200 & gtgcttggtcccaccetact & gcagcatatggagccctaga & $13 \cdot 38$ \\
\hline Pla-43_A & 53 & 490 & 250 & cccaaagcacagcatagtctg & caccctaacctggtagaagag & $C^{i} \cdot 41$ \\
\hline Pla-43_B & 56 & 510 & 210 & gcaaaagcttatggtttctgag & tagagcctcccaagtgccta & 17 \\
\hline Pla-43_C & 56 & 590 & 290 & agcaggattcaaggaagcag & gaacagtaagagagctgtggagg & $\mathrm{A}^{\mathbf{E F}} \cdot 6^{\mathbf{E F}}\left(\right.$ with $\left.^{\mathbf{E}} \sim 400 \mathrm{bp}<{ }^{\mathbf{F}}\right)$ \\
\hline Pla-43_D & 57 & 580 & 260 & cgatactgcgatgtagagagcc & gagttcctcttctcttcacagc & None \\
\hline Pla-44_A & 50 & 510 & 210 & gcttccagtagtcgttgttcc & cagcttttgctrtgttaangc & $\mathrm{A}^{\text {H. syn. }} \cdot 45$ \\
\hline Pla-44_B & 55 & 520 & 210 & tccaaagagnaaacaaaaggaa & gcctaagatgtttggggaaa & 45 \\
\hline Pla-44_C & 55 & 480 & 150 & tttggtcaaagatgggtcttc & acatcaggcatctcacttgc & None \\
\hline Pla-45_A & 55 & 580 & 280 & aacgtttggecttcatceta & ggagcagaatgnnatatggaag & $\mathrm{G} \cdot \mathrm{I} \cdot 17 \cdot 36$ \\
\hline Pla-45_B & 55 & 740 & 430 & gccaggtagccaacatcagt & ccaacarggaaatgtggtct & $\mathrm{O} \cdot 43^{\text {Alu }}$ \\
\hline Pla-45_C & 59 & 500 & 190 & gagggaggtgctgaggagta & agcagctgtgtaaacccaaaa & None \\
\hline Pla-46 & 55 & 1000 & 420 & gcacayaactttgttttgnag & ggccytatttrgcaggttgg & $\mathrm{H} \cdot \mathrm{J} \cdot \mathrm{K} \cdot \mathrm{P} \cdot 17 \cdot 18 \cdot 19 \cdot 22 \cdot 42 \cdot 45$ \\
\hline Pla-47_A & 55 & 540 & 240 & gcgagatgaatcagtgctca & aaggtggcrgcaagtagata & 16 \\
\hline Pla-47_B & 55 & 570 & 230 & gcaaagrrtgcataaaggttg & tccetgttattcytyataggttctg & None \\
\hline Pla-48_A & 56 & 660 & 320 & acaggacettttgggtttca & cytgagattgtggagaatgattt & $\mathrm{J}^{\mathbf{E F}} \cdot \mathrm{L} \cdot \mathrm{P} \cdot 17 \cdot 48^{\mathbf{E F}}$ \\
\hline Pla-48_B & 56 & 420 & 290 & atgcagcaagagacagcttg & tcccaccaaantaggactgc & $\mathrm{E} \cdot \mathrm{M}^{\mathrm{i}} \cdot \mathrm{P} \cdot 43 \cdot 46$ \\
\hline Pla-49_A & 52 & 590 & 260 & ttgaacaaaaccatcagagca & cagtngaatrcettttgcatca & None \\
\hline Pla-49_B & 54 & 650 & 340 & ccaagacagacccaatatcca & ccagccagcactttgnatca & $15^{\text {Alu }}$ \\
\hline Pla-49_C & 57 & 490 & 210 & tgaaacctcattgcagtcca & tgctccanttgcaagtatgc & $\mathrm{A}^{\text {H. syn. }} \cdot 49^{\mathbf{E F}}$ \\
\hline Pla-50_A & 55 & 530 & 230 & carnttaggyagtgtattgtgg & ctgcccaccectagactttt & 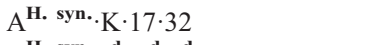 \\
\hline Pla-50_B & 56 & 620 & 310 & gagtctcacagccetccaag & tgaatctaacacctctgaatgtaggc & $A^{\text {H. syn }} \cdot E^{\mathbf{d}} \cdot G^{\mathbf{d}} \cdot 6^{\mathbf{d}} \cdot 37$ \\
\hline Pla-50_C & 58 & 500 & 200 & tgtccagaaaatggatcctga & gagttagccaaaratgyatgg & $17^{\mathrm{Alu}} \cdot 43$ \\
\hline Pla-51_A & 48 & 610 & 310 & ctgggtgcacataaacctctc & tagctcagtgacttctagacac & 14 \\
\hline Pla-51_B & 56 & 510 & 240 & aggaacaaagaggaaaggtactc & tgaattttatttggargattttga & $\mathrm{C} \cdot \mathrm{H} \cdot 42$ \\
\hline Pla-51_C & 59 & 630 & 300 & gtgaggtgggctgtgagaac & caaatggcattgtgrcaagag & $\mathrm{P}$ \\
\hline Pla-52_A & 55 & 310 & 170 & gtayataaagaraggcaaaagacycag & ttgagcacagagttgggaaa & $A^{\text {H. syn. }} \cdot E \cdot 11 \cdot 13 \cdot 14$ \\
\hline Pla-52_B & 55 & 500 & 350 & cagcagtgcctgaaaatctc & ggcnatcettgaccettagt & $\mathrm{G} \cdot \mathrm{H} \cdot \mathrm{K} \cdot \mathrm{P} \cdot 18 \cdot 19$ \\
\hline Pla-53_A & 50 & 500 & 190 & cettgaacgatgaaggcaag & tccancatagttacrtgcaagg & $G \cdot P \cdot 5 \cdot 13 \cdot 14$ \\
\hline Pla-53_B & 54 & 570 & 290 & ggatgcttatggtatggtaagtg & gaaagagagctgaaactcaggg & 45 \\
\hline Pla-53_C & 58 & 610 & 300 & ggttcatgaagctctgattgc & atcrtggagccacctctatc & $C \cdot 17 \cdot 35 \cdot 43 \cdot 44$ \\
\hline Pla-54_A & 55 & 460 & 150 & ctgcatcyctgggtctggat & tcacctgrggatcatttcca & None \\
\hline Pla-54_B & 55 & 440 & 140 & aaagaagttagcagtcatcattcaa & tgttaaccaaagcctctattaaattc & $\mathrm{P}$ \\
\hline Pla-54_C & 55 & 480 & 160 & gggtctgacctaagagaactgg & gattgttgaagggagggtca & None \\
\hline Pla-54_D & 55 & 480 & 190 & aaaaagatgtcccatgttcaaga & rggcttcacacagaaagcac & None \\
\hline Ant-55_A & 50 & 650 & 350 & gctagggagaatgatgatgaag & aattaggtattccetttaaytcaca & $P \cdot 41 \cdot 56 \cdot 61$ \\
\hline Ant-55_B & 60 & 880 & 580 & gcagcaatgtaaaggcaattagttc & gcattttgattccccaggag & $C \cdot 19^{\mathrm{i}} \cdot 29 \cdot 44$ \\
\hline Ant-55_C & 50 & 1060 & 730 & ggaaaattgcaaaagcatatctac & atgcatttttgtcgttccag & $P \cdot 61$ \\
\hline Ant-55_D & 60 & 500 & 280 & gaagaatggaaagaaattgtgtagc & aagctggggattcattcataaaatac & $\mathrm{P}$ \\
\hline Ant-55_E & 60 & 1100 & 700 & gcattttattagctccaagttcaag & agttaatacccaggatgagaatgg & None \\
\hline Tar-56 & & 650 & 350 & Same primer as Str-71_C & same primer as Str-71_C & $71^{\text {Alu }}$ \\
\hline Str-57_A & 55 & 840 & 500 & tgtttcaaagatcaaatgtcatgg & cccaaggggagacagaagtt & $\mathrm{P}^{\mathrm{i}-(\sim 300 \mathrm{bp})} \cdot \mathrm{Q} \cdot 46^{\mathrm{i}-(\sim 300 \mathrm{bp})} \cdot 56^{\mathrm{i}} \cdot 65$ \\
\hline Str-57_B & 58 & 640 & 300 & agratcctggaatactgrtcct & gctgagatgyatccetccyg & $\mathrm{L} \cdot 56^{\text {T. syr }} \cdot 59$ \\
\hline Str-57_C & 54 & 880 & 580 & caccacaactaccetggaagr & agaactctccttbacttaacctgtttc & $L \cdot T \cdot X \cdot 56 \cdot 65$ \\
\hline Str-58_A & 52 & 520 & 160 & atagccthtgcaggtcraag & gagcttaatatataavtwttctcaac & $\mathrm{H}^{\mathrm{i}} \cdot 56 \cdot 61$ \\
\hline Str-58_B & 53 & 570 & 220 & cettgtgacctctgaagtaaaractc & tgactctgtgtybttgtctaaactag & None \\
\hline Str-59 & 60 & 1060 & 750 & tacccagtgctcatttggatc & gcaatcagcaaatgcttgttttag & None \\
\hline Str-60 & & 1000 & 650 & Same primer as Str-66_A & same primer as Str-66_A & $W^{\text {only Str-65 Alu }} \cdot 66^{\text {Alu }}$ \\
\hline Str-61 & 58 & 1070 & 760 & gcccagtttgtaattcttgatttc & gcaacccagctwacttcagagg & 56 \\
\hline Str-62 & 55 & 970 & 620 & ctcactttcraaaatagcctactgc & aaggtcagtgttccytctctkc & 46 \\
\hline Str-63_A & 50 & 550 & 250 & tectctrtgactctyytgagttag & ggcacawttaagctatattrthcaa & $X \cdot 56 \cdot 65$ \\
\hline Str-63_B & 53 & 480 & 220 & aggaagaggctgrtgraagg & gaatttcamatttttaggctcag & $\mathrm{F} \cdot \mathrm{S} \cdot 56$ \\
\hline Str-64 & 55 & 650 & 300 & tgaggcaartaaatatcttgakagc & tggagccettgcwgtyg & $\mathrm{F} \cdot \mathrm{H} \cdot \mathrm{T}^{\mathbf{E F}} \cdot \mathrm{V}^{\mathrm{d}} \cdot 27^{\mathrm{d}} \cdot 43 \cdot 56^{\mathrm{T} \cdot \text { buc }} \cdot 69$ \\
\hline Str-65 & & 720 & 650 & Same primer as Str-66_A & same primer as Str-66_A & $60^{\mathrm{Alu}} \cdot 66^{\mathrm{Alu}}$ \\
\hline Str-66_A & 58 & 950 & 650 & ctgcctcttaccatatttgacttc & gcctattcacatccatcactc & $\mathrm{W}^{\text {Str-65 Alu }} \cdot 60^{\text {Alu + Str-65 Alu }}$ \\
\hline Str-66_B & 60 & 980 & 680 & gatgctaatgtggcttaatctcag & agccagctcttgaaatgtgc & $\mathrm{H} \cdot 65$ \\
\hline Str-67 & 53 & 910 & 550 & gctttctgcatrggaggtagaataat & ccaatatcdtggcattctgtwaactc & $\mathrm{L} \cdot \mathrm{S} \cdot 34 \cdot 43 \cdot 56^{\mathbf{T} \cdot \mathbf{s y r}}$ \\
\hline Str-68 & 55 & 1060 & 740 & aggctacagattttcaagatttacc & ctttagagccetctgctgga & 42 \\
\hline Str-69_A & 55 & 990 & 690 & gctgtgccaaagaaatcagg & ggcacatttcctttgtttggag & None \\
\hline Str-69_B & 53 & 610 & 400 & tgggraaaatgtttggcagat & tgtgattcattctttggagca & $\mathrm{L}^{\mathrm{i}}$ \\
\hline Str-70_A & 54 & 600 & 300 & gtgyatgtrtgttggggcaar & cacttcytagcytgrtggcttt & $\mathrm{V}^{\mathbf{E F}} \cdot \mathrm{T}^{\mathrm{i}} \cdot 47 \cdot 56 \cdot 60 \cdot 61$ \\
\hline Str-70_B & 56 & 610 & 310 & matacagtgaatacttgaatgkgc & taatcactaatgaaaatgtatctgarag & $\mathrm{U} \cdot 7 \cdot 42 \cdot 54^{\mathrm{i}} \cdot 56 \cdot 61 \cdot 65$ \\
\hline Str-71_A & 52 & 500 & 190 & cctagcetttgtgaggraagtr & gttcagaagaayccattaycaytg & $\mathrm{P} \cdot \mathrm{T} \cdot 44 \cdot 46 \cdot 56 \cdot 62 \cdot 65$ \\
\hline Str-71_B & 48 & 470 & 170 & gtcttattggatargaagaanctagg & gcctaaggtdcaaahttgtctc & $P \cdot 56 \cdot 65$ \\
\hline
\end{tabular}


Appendix B (continued)

\begin{tabular}{|c|c|c|c|c|c|c|}
\hline Primer $^{\mathrm{a}}$ & $\mathrm{AT}^{\mathrm{b}}$ & Fill $^{\mathrm{c}}$ & Null & Forward primer $\left(5^{\prime}-3^{\prime}\right)$ & Reverse primer $\left(5^{\prime}-3^{\prime}\right)$ & Atypical amplification ${ }^{\mathrm{d}}$ \\
\hline Str-71_C & 55 & 650 & 350 & tgtgctatccetttttaggrmtg & caacacaaaayvttgtcttaatrgg & $S \cdot 42 \cdot 52 \cdot 56^{\text {Alu }}$ \\
\hline Str-72 & 50 & 1020 & 700 & ttcartttcactggraatcctttag & agagatcwtcagaactatgeccttr & $16 \cdot 43 \cdot 56$ \\
\hline Str-73_A & 54 & 580 & 200 & ccatttaggaagatgtgycatg & tgcttcactgagatamaagavga & $\mathrm{P} \cdot \mathrm{X} \cdot 17^{\mathrm{Alu}} \cdot 42^{\mathrm{i}-(\mathbf{2} \text { bands })+\mathrm{Alu}} \cdot 45$ \\
\hline Str-73_C & 60 & 550 & 280 & gaagggaagasagtttcctaarc & aacaccacctkataaccarcc & $S \cdot 44^{i} \cdot 50 \cdot 51 \cdot 65$ \\
\hline Str-73_D & 55 & 790 & 410 & ggcccacaaaaattaaatcag & atagggtttcccaggaaattayagc & 56 \\
\hline
\end{tabular}

${ }^{\text {a }}$ Primer designations: Hom, Hominids; Cat, Catarrhini; Cer, Cercopithecidae; Pla, Platyrrhini; Tar, Tarsiformes; and Str, Strepsirrhini. Numbers are keyed to branches in Fig. 1, which are defined by the insertion of an Alu element at the associated loci.

${ }^{\mathrm{b}}$ AT, Annealing temperature $\left({ }^{\circ} \mathrm{C}\right)$.

${ }^{c}$ Fragment sizes (bp) of filled and empty sites are approximate and should be used only as a guide for gel interpretation.

${ }^{d}$ Branches in Fig. 1 for which PCR of a locus gave atypical results: (I) no amplification or multiple fragments (no superscript label); (II) fragments $>50$ bp larger (') or smaller $\left({ }^{\mathbf{d}}\right)$ than expected; (III) independent insertion ( ${ }^{\text {Alu }}$ ); or (IV) two fragments having the approximate sizes of empty and filled alleles ${ }^{(\mathbf{E F})}$. Further PCR optimization might improve or eliminate these atypical results. With the exception of some loci on Branches 40 and 55 as well as the clade defined by Branch 73 , PCR with DNA from Strepsirrhines and Tarsiformes usually resulted in no amplification or multiple fragments.

\section{References}

Altschul, S.F., Gish, W., Miller, W., Myers, E.W., Lipman, D.J., 1990. Basic local alignment search tool. J. Mol. Biol. 215, 403-410.

Badge, R.M., Alisch, R.S., Moran, J.V., 2003. ATLAS: a system to selectively identify human-specific L1 insertions. Am. J. Hum. Genet. 72, 823-838.

Batzer, M.A., Deininger, P.L., 2002. Alu repeats and human genomic diversity. Nat. Rev., Genet. 3, 370-379.

Biedler, J., Qi, Y., Holligan, D., della Torre, A., Wessler, S., Tu, Z., 2003. Transposable element (TE) display and rapid detection of TE insertion polymorphism in the Anopheles gambiae species complex. Insect Mol. Biol. 12, 211-216.

Brody, J.R., Kern, S.E., 2004a. History and principles of conductive media for standard DNA electrophoresis. Anal. Biochem. 333, 1-13.

Brody, J.R., Kern, S.E., 2004b. Sodium boric acid: a Tris-free, cooler conductive medium for DNA electrophoresis. Biotechniques 36, 214-216.

Deininger, P.L., Batzer, M.A., 2002. Mammalian retroelements. Genome Res. $12,1455-1465$.

Disotell, T., 2003. Primates: Phylogenetics. Nature Publishing Group.

Domingo-Roura, X., Marmi, J., Ferrando, A., Lopez-Giraldez, F., Macdonald, D.W., Jansman, H.A.H., 2006. Badger hair in shaving brushes comes from protected Eurasian badgers. Biol. Conserv. 128, 425-430.

Hall, T.A., 1999. BioEdit: a user-friendly biological sequence alignment editor and analysis program for Windows 95/98/NT. Nucleic Acids Symp. Ser. 95-98.

Hamdi, H., Nishio, H., Zielinski, R., Dugaiczyk, A., 1999. Origin and phylogenetic distribution of Alu DNA repeats: irreversible events in the evolution of primates. J. Mol. Biol. 289, 861-871.

Han, K., et al., 2005. Under the genomic radar: the stealth model of Alu amplification. Genome Res. 15, 655-664.

Hebert, P.D., Stoeckle, M.Y., Zemlak, T.S., Francis, C.M., 2004. Identification of birds through DNA barcodes. PLoS Biol. 2, e312.

Hillis, D.M., 1999. SINEs of the perfect character. Proc. Natl. Acad. Sci. U. S. A. 96, 9979-9981.

Hsieh, H.M., et al., 2003. Species identification of rhinoceros horns using the cytochrome $b$ gene. Forensic Sci. Int. 136, 1-11.

Kohn, M., Knauer, F., Stoffella, A., Schroder, W., Paabo, S., 1995. Conservation genetics of the European brown bear-a study using excremental PCR of nuclear and mitochondrial sequences. Mol. Ecol. 4, 95-103.

Kriegs, J.O., Churakov, G., Kiefmann, M., Jordan, U., Brosius, J., Schmitz, J., 2006. Retroposed elements as archives for the evolutionary history of placental mammals. PLoS Biol. 4.

Kumar, S., Tamura, K., Nei, M., 2004. MEGA3: integrated software for molecular evolutionary genetics analysis and sequence alignment. Brief. Bioinform. 5, 150-163.

Lander, E.S., et al., 2001. Initial sequencing and analysis of the human genome. Nature 409, 860-921.

Lathuilliere, M., Menard, N., Gautier-Hion, A., Crouau-Roy, B., 2001. Testing the reliability of noninvasive genetic sampling by comparing analyses of blood and fecal samples in Barbary macaques (Macaca sylvanus). Am. J. Primatol. 55, 151-158.
Lorenz, J.G., Jackson, W.E., Beck, J.C., Hanner, R., 2005. The problems and promise of DNA barcodes for species diagnosis of primate biomaterials. Philos. Trans. R. Soc. Lond., B Biol. Sci. 360, 1869-1877.

Malisa, A., Gwakisa, P., Balthazary, S., Wasser, S., Mutayoba, B., 2005. Species and gender differentiation between and among domestic and wild animals using mitochondrial and sex-linked DNA markers. Afr. J. Biotechnol. 4, 1269-1274.

Matsubara, M., et al., 2005. Species and sex identification of western lowland gorillas (Gorilla gorilla gorilla), eastern lowland gorillas (Gorilla beringei graueri) and humans. Primates 46, 199-202.

Moritz, C., Cicero, C., 2004. DNA barcoding: promise and pitfalls. PLoS Biol. 2 e354.

Nikaido, M., Rooney, A.P., Okada, N., 1999. Phylogenetic relationships among cetartiodactyls based on insertions of short and long interspersed elements: hippopotamuses are the closest extant relatives of whales. Proc. Natl. Acad. Sci. U. S. A. 96, 10261-10266.

Nikaido, M., et al., 2006. Baleen whale phylogeny and a past extensive radiation event revealed by SINE insertion analysis. Mol. Biol. Evol. 23, 866-873.

Okada, N., Shedlock, A.M., Nikaido, M., 2004. Retroposon mapping in molecular systematics. Methods Mol. Biol. 260, 189-226.

Palumbi, S.R., Cipriano, F., 1998. Species identification using genetic tools: the value of nuclear and mitochondrial gene sequences in whale conservation. J. Heredity 89, 459-464.

Perna, N.T., Batzer, M.A., Deininger, P.L., Stoneking, M., 1992. Alu insertion polymorphism: a new type of marker for human population studies. Hum. Biol. 64, 641-648.

Ray, D.A., et al., 2005a. Inference of human geographic origins using Alu insertion polymorphisms. Forensic Sci. Int. 153, 117-124.

Ray, D.A., et al., 2005b. Alu insertion loci and platyrrhine primate phylogeny. Mol. Phylogenet. Evol. 35, 117-126.

Ray, D.A., Xing, J., Salem, A.-H, Batzer, M.A., in press. SINEs of a nearly perfect character. Systematic Biology.

Roos, C., Schmitz, J., Zischler, H., 2004. Primate jumping genes elucidate strepsirrhine phylogeny. Proc. Natl. Acad. Sci. U. S. A. 101, 10650-10654.

Roy, A.M., et al., 1999. Recently integrated human Alu repeats: finding needles in the haystack. Genetica 107, 149-161.

Roy-Engel, A.M., et al., 2002. Non-traditional Alu evolution and primate genomic diversity. J. Mol. Biol. 316, 1033-1040.

Rozen, S., Skaletsky, H., 2000. Primer3 on the WWW for general users and for biologist programmers. Methods Mol. Biol. 132, 365-386.

Salem, A.H., Kilroy, G.E., Watkins, W.S., Jorde, L.B., Batzer, M.A., 2003 a. Recently integrated Alu elements and human genomic diversity. Mol. Biol. Evol. 20, 1349-1361.

Salem, A.H., et al., 2003b. Alu elements and hominid phylogenetics. Proc. Natl. Acad. Sci. U. S. A. 100, 12787-12791.

Salem, A.H., Ray, D.A., Batzer, M.A., 2005. Identity by descent and DNA sequence variation of human SINE and LINE elements. Cytogenet. Genome Res. 108, 63-72. 
Sanger, F., Nicklen, S., Coulson, A.R., 1977. DNA sequencing with chainterminating inhibitors. Proc. Natl. Acad. Sci. U. S. A. 74, 5463-5467.

Schmitz, J., Ohme, M., Zischler, H., 2001. SINE insertions in cladistic analyses and the phylogenetic affiliations of Tarsius bancanus to other primates. Genetics 157, 777-784.

Schmitz, J., Roos, C., Zischler, H., 2005. Primate phylogeny: molecular evidence from retroposons. Cytogenet. Genome Res. 108, 26-37.

Schwartz, S., et al., 2000. PipMaker - a Web server for aligning two genomic DNA sequences. Genome Res. 10, 577-586.

Shedlock, A.M., Okada, N., 2000. SINE insertions: powerful tools for molecular systematics. BioEssays $22,148-160$

Shedlock, A.M., Takahashi, K., Okada, N., 2004. SINEs of speciation: tracking lineages with retroposons. Trends Ecol. Evol. 19, 545-553.

Sheen, F.M., et al., 2000. Reading between the LINEs: human genomic variation induced by LINE-1 retrotransposition. Genome Res. 10, 1496-1508.

Taberlet, P., et al., 1997. Noninvasive genetic tracking of the endangered Pyrenean brown bear population. Mol. Ecol. 6, 869-876.

Thompson, J.D., Higgins, D.G., Gibson, T.J., 1994. CLUSTAL W: improving the sensitivity of progressive multiple sequence alignment through sequence weighting, position-specific gap penalties and weight matrix choice. Nucleic Acids Res. 22, 4673-4680.

Ustyugova, S.V., Amosova, A.L., Lebedev, Y.B., Sverdlov, E.D., 2005. Cell line fingerprinting using retroelement insertion polymorphism. Biotechniques $38,561-565$.

Van de Lagemaat, L.N., Gagnier, L., Medstrand, P., Mager, D.L., 2005. Genomic deletions and precise removal of transposable elements mediated by short identical DNA segments in primates. Genome Res. 15, 1243-1249.
Waddell, P.J., Kishino, H., Ota, R., 2001. A phylogenetic foundation for comparative mammalian genomics. Genome Inf. Ser. Workshop Genome Inf. 12, 141-154.

Walker, J.A., Hughes, D.A., Anders, B.A., Shewale, J., Sinha, S.K., Batzer, M.A., 2003a. Quantitative intra-short interspersed element PCR for species-specific DNA identification. Anal. Biochem. 316, 259-269.

Walker, J.A., Kilroy, G.E., Xing, J., Shewale, J., Sinha, S.K., Batzer, M.A., 2003b. Human DNA quantitation using Alu element-based polymerase chain reaction. Anal. Biochem. 315, 122-128.

Walker, J.A., Garber, R.K., Hedges, D.J., Kilroy, G.E., Xing, J., Batzer, M.A., 2004a. Resolution of mixed human DNA samples using mitochondrial DNA sequence variants. Anal. Biochem. 325, 171-173.

Walker, J.A., et al., 2004b. Quantitative PCR for DNA identification based on genome-specific interspersed repetitive elements. Genomics 83, 518-527.

Walker, J.A., et al., 2005. Multiplex polymerase chain reaction for simultaneous quantitation of human nuclear, mitochondrial, and male Y-chromosome DNA: application in human identification. Anal. Biochem. 337, 89-97.

Wolfe, N.D., et al., 2005. Emergence of unique primate T-lymphotropic viruses among central African bushmeat hunters. Proc. Natl. Acad. Sci. U. S. A. 102, 7994-7999.

Xing, J., et al., 2005. A mobile element based phylogeny of Old World monkeys. Mol. Phylogenet. Evol. 37, 872-880.

Yan, P., Wu, X.B., Shi, Y., Gu, C.M., Wang, R.P., Wang, C.L., 2005. Identification of Chinese alligators (Alligator sinensis) meat by diagnostic PCR of the mitochondrial cytochrome $b$ gene. Biol. Conserv. 121, 45-51. 